\title{
GLUCOSE UTILIZATION IN THE AUDITORY SYSTEM: COCHLEAR DYSFUNCTIONS AND SPECIES DIFFERENCES
}

\author{
Barbara Canlon, Akira Takada and Jochen Schacht \\ Kresge Hearing Research Institute, The University of Michigan, Am Arbor, MI 48109, USA.
} Telephone: (313) 764-5196

(Received 23 August 1983)

\begin{abstract}
Deoxyglucose uptake in peripheral auditory tissues and inferior colliculus of the young CBA or C57BL/6J mouse increases with intensity of an acoustic stimulus from 25 to $85 \mathrm{dBA}$ and decreases from 85 to $115 \mathrm{dBA}$.

2. In 36-month-old $\mathrm{CBA}$ and 9-month-old $\mathrm{C} 57 \mathrm{BL}$ with sensorineural hearing loss the metabolic response to stimulation is attenuated $50 \%$ or more.

3. Metabolic responses to stimuli are qualitatively and quantitatively different in the gerbil and in the guinea-pig.

4. It is concluded that cochlear dysfunctions are characterized by abnormal evoked metabolism; and that the stimulus-response pattern varies with species.
\end{abstract}

\section{INTRODUCTION}

Although our present understanding of metabolism and blood circulation in the human inner ear is rudimentary, disorders of both have been implicated as an underlying cause for several inner ear dysfunctions. Anatomical studies have shown pathological changes in cochlear blood vessels in patients with severe presbyacusis (Johnsson and Hawkins, 1972); sudden hearing loss and fluctuating hearing loss have been suggested to have a similar etiology (Mazzoni, 1969. Maass, 1981). While direct evidence is scant and controversial, animal experiments show that alterations in cochlear blood flow can directly affect local metabolism and auditory thresholds. For instance, by experimentally limiting the blood supply to the cochlea, Thalmann et al. (1972) induced a concurrent decrease in cochlear potentials and energy metabolites in cochlear tissues. Little is known, however, how blood flow or metabolism is affected in animal models of certain cochlear disorders.

With the development of the 2-deoxyglucose technique for both animals (Sokoloff et al., 1977) and humans (Reivich et al., 1977), it has been firmly established that physiological stimuli evoke increased energy metabolism in discrete regions of the central nervous system (Phelps et al., 1979; Alavi et al., 1981; Sokoloff, 1981). We have recently reported alterations of deoxyglucose uptake in the cochlea of the normal mouse during acoustic stimulation (Canlon and Schacht, 1983). The aim of the present study was to determine whether the response of glucose metabolism to auditory stimulation is altered in cochlear dysfunctions. We chose the aged CBA mouse and the C57BL/6J mouse, a mutant with genetically determined progressive hearing loss, as animal models for sensory hearing loss. Furthermore, since species differences are known to exist in anatomy and in electrophysiological responses of the auditory system we tested the metabolic response to acoustic stimu- lation in the gerbil and the guinea-pig. This knowledge is essential before generalizations about auditory metabolism can be made.

\section{MATERIALS AND METHODS}

Animals

Four-month-old CBA and C57BL/6J mice (Mus musculus, 18-22 g) as well as male CBA mice, 36 months of age (24-28 g) were obtained from the Jackson Laboratory, Bar Harbor, MA; Mongolian gerbils (Meriones unguiculatus, $50-60 \mathrm{~g}$ ) from Tumblebrook Farms, West Brookficld. MA. and albino guinea pigs (Cavia cobaya, 200-250 g) from Charles River, Wilmington, MA. All animals had been maintained on Purina Laboratory Chow and water ad lib. in a pathogen-free area with exposure to ambient sound The aged $C B A$ mice were provided through the National Institute on Aging.

\section{Deoxyglucose uptake}

Conscious mice and gerbils received a single injection of $5 \mathrm{mCi}\left[{ }^{3} \mathrm{H}\right.$ )deoxyglucose $/ \mathrm{kg}$ body weight (Pathfinder Lab., St. Louis, $\mathrm{MO}$; specific activity, $40 \mathrm{mCl} / \mathrm{mmol}$ ) into either the tail vein (mice) or by intracardiac puncture (gerbils). Immediately after the injection animals were placed in a sound shielded exposure box for $60 \mathrm{~min}$. The animals were then killed by decapitation and blood samples taken. Inner ear fluids were absorbed with cotton swabs and the brain and auditory bulla were exposed to microwave irradiation for $15 \mathrm{sec}$ to arrest enzymatic activities. The cochlear tissues were dissected, homogenized, and analyzed for protein (Lowry et al., 1952), and radioactivity. Deoxyglucose-6phosphate was separated from deoxyglucose by ion exchange chromatography (Hassell et al., 1975). A more complete description of the technique is given elsewhere (Canlon and Schacht, 1983).

\section{Cochlear perfusions}

Perilymphatic perfusions were carried out in guinea pigs as previously described (Takada and Schacht, 1982). In brief, glass capillaries were implanted into scala tympani and scala vestibuli of the basal turn of the cochlea after a conventional ventral surgical approach. Artificial perilymph 
containing $10 \mu \mathrm{Ci}\left[{ }^{3} \mathrm{H}\right]$ deoxyglucose/ml was perfused for $60 \mathrm{~min}$ at a rate of approximatcly $30 \mu \mathrm{l} / \mathrm{min}$. The cochlear microphonic potential was periodically monitored via a recording electrode in scala tympani. At the end of the experiment the animal was decapitated, the cochlea removed and tissues were processed as above.

\section{Sound exposure}

Auditory stimuli were presented to mice and gerbils as free-field broadband noise $(100 \mathrm{~Hz}-45 \mathrm{kHz})$ at intensities of up to $115 \mathrm{dBA}$. The spectrum was flat to $20 \mathrm{kHz}$ and attenuated approximately $20 \mathrm{~dB}$ between 20 and $45 \mathrm{kHz}$. Noise levels were measured with a half inch condenser microphone on the dBA scale. The exposure box $(40 \times 40 \times 40 \mathrm{~cm})$ was placed inside a soundproof booth in order to obtain the lowest noise level (25 dBA). For the guinea pigs broadband noise $(50 \mathrm{~Hz}-10 \mathrm{kHz})$ at intensities up to $100 \mathrm{~dB}$ was delivered by a calibrated earphone attached to a speculum placed directly before the tympanic membrane. Attenuation at $3 \mathrm{kHz}$ was approximately $10 \mathrm{~dB}$, at $5 \mathrm{kHz}$ approximately $25 \mathrm{~dB}$. To attain the lowest possible noise level in an ambient environment, the incudostapedial joint was separated.

\section{Calculations}

For mice and gerbils, deoxyglucose uptake was calculated from the radioactivity in the tissue per $\mu \mathrm{g}$ tissue protein and corrected for the serum levels of $\left[{ }^{3} \mathrm{H}\right]$ deoxyglucose (Canlon and Schacht, 1983). For comparisons, activity is expressed relative to the "basal" activity at the lowest attainable noise level. For the guinea-pig, uptake was calculated from tissue radioactivity per $\mu \mathrm{g}$ tissue protein and corrected for the concentration of $\left[{ }^{3} \mathrm{H}\right]$ deoxyglucose in the perfusate.

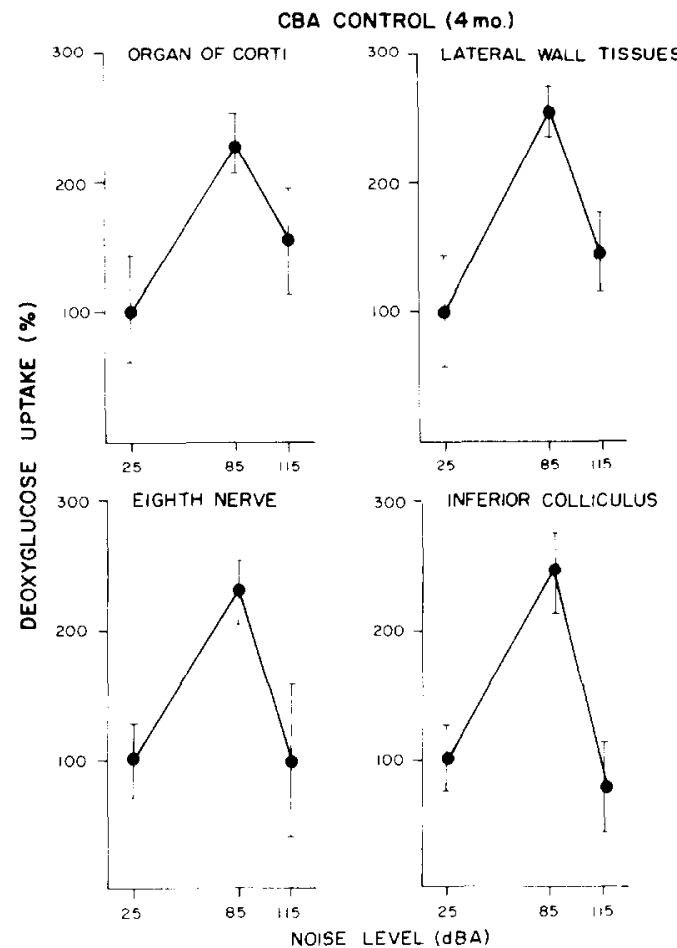

Fig. 1. Response of deoxyglucose uptake to noise exposure in young CBA mice. Animals (4 months old) received a pulse of $5 \mathrm{mCi}\left[{ }^{3} \mathrm{H}\right]$ deoxyglucose $/ \mathrm{kg}$ body weight and were killed after $60 \mathrm{~min}$ of exposure to the noise levels indicated. Deoxyglucosc uptake was determined as described in the "Materials and Methods" section. Basal rates (at $25 \mathrm{dBA}$, i.e., $100 \%$ were organ of Corti, $5.6 \pm 2.2(N=8)$; lateral wall, $6.5 \pm 3.1(8)$; VIIIth nerve, $6.7 \pm 1.9(7)$ and inferior colliculus $7.9 \pm 2.2$ (14) (Canlon and Schacht, 1983).

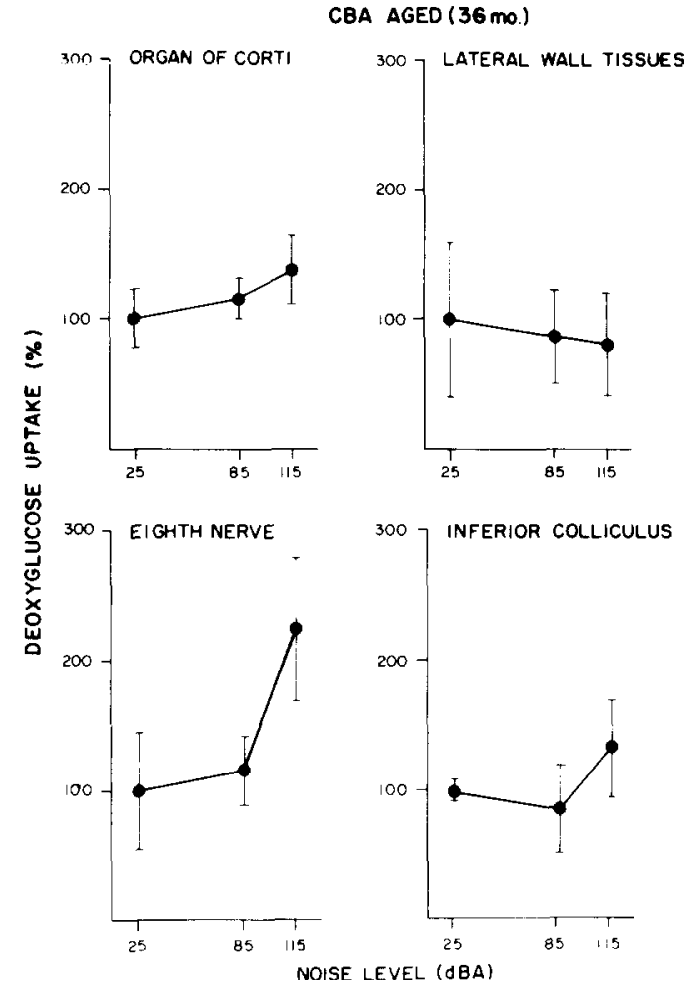

Fig. 2. Response of deoxyglucose uptake to noise exposure in aged CBA mice. Animals (36 months old) were treated as in Fig. 1 and the "Materials and Methods" section. Basal rates (at $25 \mathrm{dBA}$, i.e., $100 \%$ ) were organ of Corti, $3.5 \pm 0.8$; lateral wall, $7.1 \pm 4.4$; VIIIth nerve, $3.6 \pm 1.8$; inferior colliculus $14.2 \pm 1.1$. Values are means $\pm S D$ from four animals each.

\section{RESULTS}

The effect of auditory stimulation on cochlear metabolism in the 36-month-old CBA mouse was compared to the 4-month-old CBA mouse. For the latter, we previously reported a biphasic response to auditory stimulation in the neural auditory structures as well as the lateral wall tissues (Canlon and Schacht, 1983). Cochlear metabolism is represented (Fig. 1) at the critical intensities of 25-85-115 dBA, which correspond to the basal activity, the maximum stimulated response and the decrease from the maximum, respectively. In the aged CBA mouse (Fig. 2), the metabolic response shows a different pattern: at $85 \mathrm{dBA}$ it is approximately $50 \%$ lower and at higher intensities there is a suggestion of further increased metabolism in the eighth nerve and inferior colliculus, and to a lesser extent, the organ of Corti. Even at the high intensity (115 dBA) glucose uptake is stimulated less than at $85 \mathrm{dBA}$ in the young, and there is no evidence of a biphasic response.

The C57BL/6J mouse at 3 months of age demonstrated a similar biphasic response to noise stimulation as the young CBA (Fig. 3). The 9-month-old C57BL/6J mouse still displayed a biphasic response to noise stimulation yet the maximum was reduced by approximately $50 \%$ (Fig. 4).

The auditory tissues of the gerbil show a linear response to noise and a lesser stimulation; only at 
$\mathrm{C} 57 / \mathrm{b} / 6(3 \mathrm{mo}$.
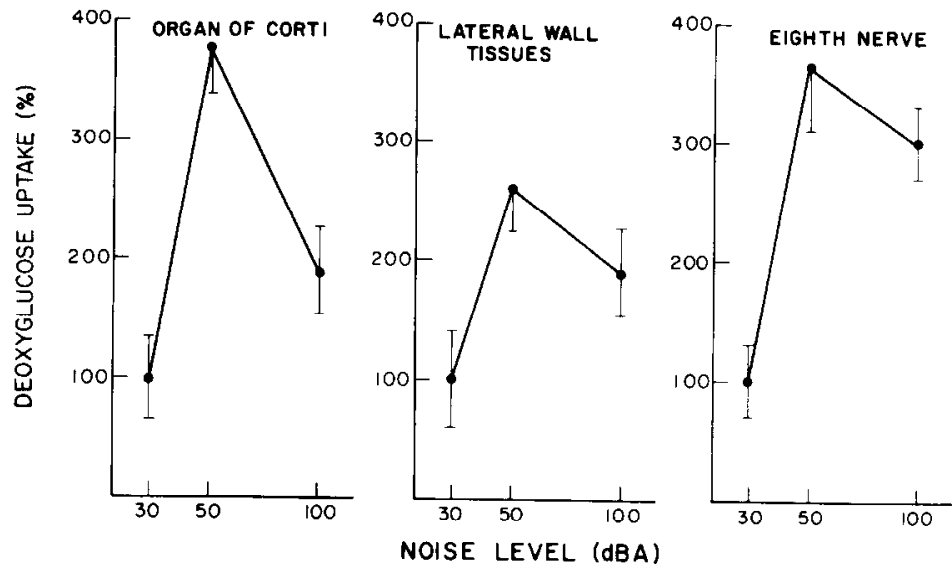

Fig. 3. Response of deoxyglucose uptake to noise exposure in young C57BL/6J mice. Animals (3 months old) were treated as in Fig. 1 and "Materials and Methods" section. Basal rates (at $30 \mathrm{dBA}$, i.e. $100 \%$; organ of Corti, $2.1 \pm 0.7$; lateral wall, $3.2 \pm 1.3$; VIIIth nerve $2.6 \pm 0.8$. Values are means $\pm S D$ from three animals each.

$115 \mathrm{dBA}$ does the deoxyglucose uptake reach a relative magnitude comparable to that in the mouse at 85 dBA (Fig. 5). A biphasic response could not be observed at the intensities tested.

Deoxyglucose uptake in the guinea pig cochlea was studied by continuous perilymphatic perfusion. The

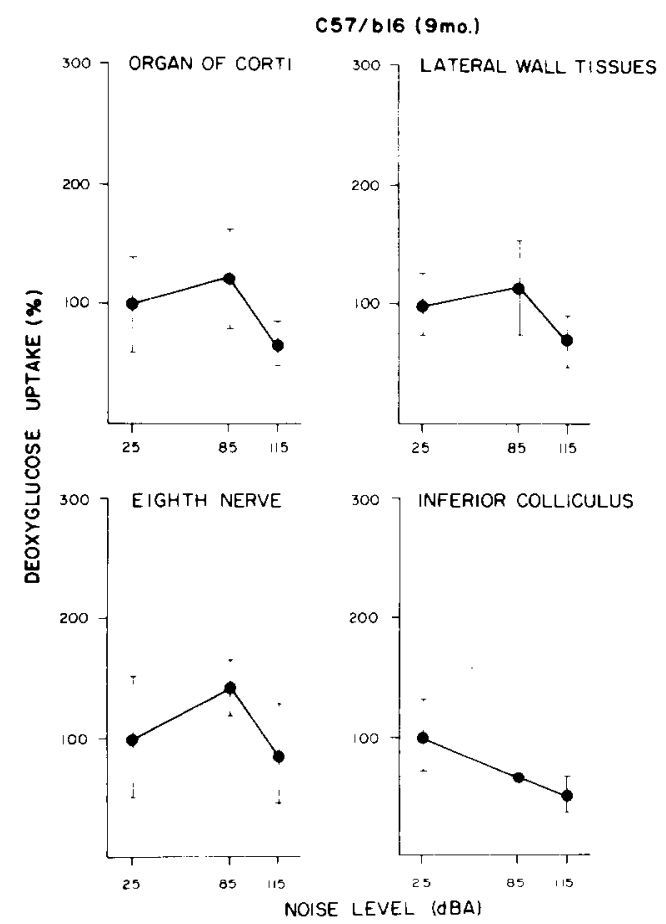

Fig. 4. Response of deoxyglucose uptake to noise exposure in 9-month-old $\mathrm{C} 57 \mathrm{BL} / 6 \mathrm{~J}$ mice. Animals were treated as in Fig. 1 and "Materials and Methods" section. Basal rates $(25 \mathrm{dBA}$, i.e. $100 \%)$ were organ of Corti $4.7 \pm 2.1$; lateral wall, $6.9 \pm 1.8$; VIIIth nerve $5.7 \pm 3.4$; inferior colliculus $18.2 \pm 5.8$. Values are means \pm SD from three animals each. time course for incorporation of $\left[{ }^{3} \mathrm{H}\right]$ deoxyglucose was linear up to $2 \mathrm{hr}$, the longest time investigated. After $60 \mathrm{~min}$, steady state levels of deoxyglucose-6phosphate were attained. There was no significant increase in metabolism in response to noise of $25-100 \mathrm{~dB}$ (Fig. 6).

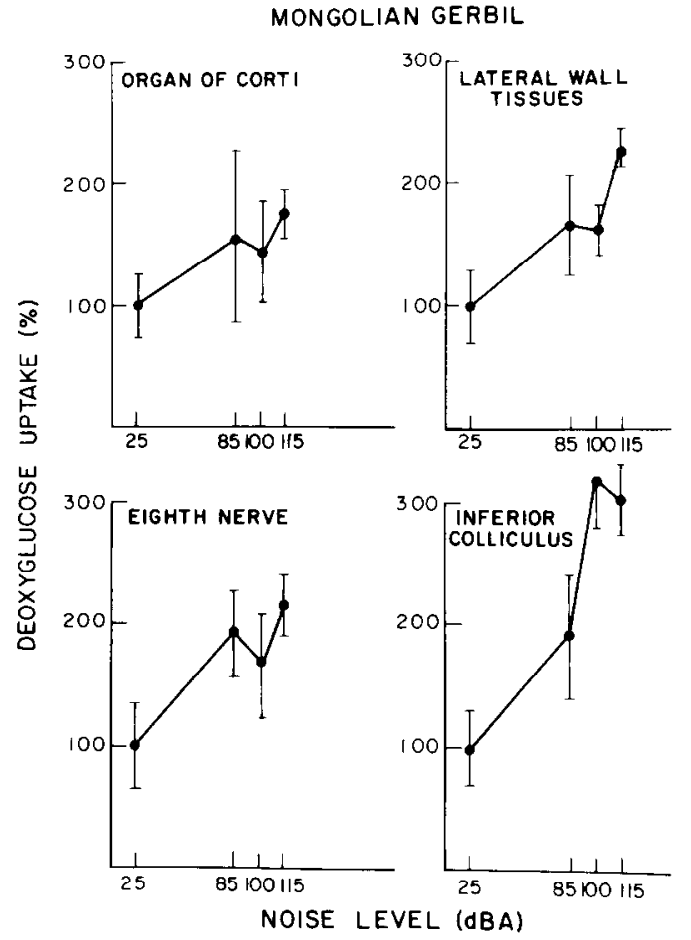

Fig. 5. Response of deoxyglucose uptake to noise in Mongolian gerbils. Animals ( $3-4$ months old) were treated as in Fig. 1 and "Materials and Methods" section. Basal rates ( $25 \mathrm{dBA}$, i.e. $100 \%$ ) were organ of Corti $5.5 \pm 1.5$; lateral wall $5.0 \pm 1.3$; VIIIth nerve $4.2 \pm 1.6$; inferior colliculus $5.2 \pm 1.8$. Values are means $\pm S D$ of $3-4$ animals each. 

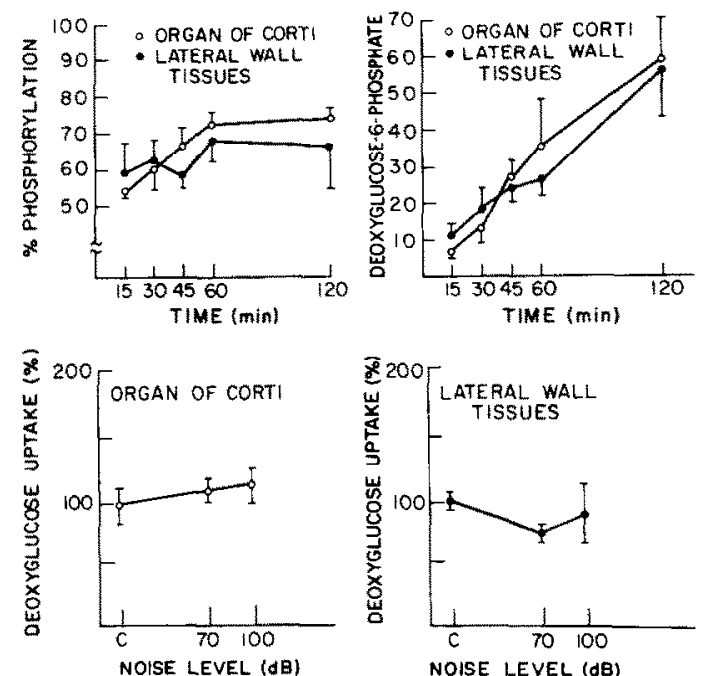

Fig. 6. Deoxyglucose uptake in the guinea-pig cochlea. Animals received perilymphatic perfusions with deoxyglucose $(10 \mu \mathrm{Ci} / \mathrm{ml})$ as described in "Materials and Methods" section. Upper panels: time course of phosphorylation and of accumulation of deoxyglucose-6phosphate. I ower panels: effect of noise on deoxyglucose uptake. " $\mathrm{C}$ " on $x$-axis indicates lowest noise level achieved by separating the incudostapedial joint. Values are means \pm SD of 4-6 animals each.

\section{DISCUSSION}

Cochlear glucose utilization in response to acoustic stimulation is significantly changed in the aged CBA and the elder C57BL/6J mouse. It should be emphasized that in this study we compare the magnitude of the metabolic response and the stimulus-response pattern only. Other comparisons, e.g. of metabolic rates between species, would require knowledge of the "lumped constant" but its determination for individual inner ear tissues is technically not feasible (Canlon and Schacht, 1983). Even comparisons of metabolic rates between young and old animals of the same strain may be influenced by a change in the lumped constant with age (Takei et al., 1983).

The reduced metabolic response in aged animals of both strains appears to correlate with reported morphological and electrophysiological findings of degenerative changes of the peripheral auditory system. Morphological studies have established hair cell and nerve fiber pathology with increasing age in humans (Johnsson and Hawkins, 1972), rats (Keithley and Feldman, 1982) and C57BL/6J mutants (Mikaelian, 1979), as well as in the CBA mice used in this study (Hawkins, personal communication). In addition, the electrical response to sound is depressed with age as shown in guinea pigs (Pestalozza et al., 1957), rats (Crowley et al, 1972), C57BL/6J mutants (Mikaelian, 1979), and in the aged CBA mice (Nuttall, personal communication). It is thus conceivable that the loss of sensory cells is the cause of the depressed metabolic response to acoustic stimulation. It remains open, however, whether a metabolic deficiency may have preceded and caused physiological dysfunction and anatomical pathology.

In contrast to the depression of stimulated metabolism, the values measured at the lowest attainable noise level did not change in any consistent pattern with age in the CBA and C57BL/6J mice. Even considering the possibility of altered lumped constants with age it is evident that the evoked response of auditory structures is more clearly affected than the apparent basal metabolism. This appears essentially in agreement with a report that central auditory pathways showed reduced glucose utilization in aged rats at ambient (i.e. stimulatory) noise levels (Smith et al., 1980).

The second aim of this study was to determine whether auditory metabolism is as varied among species as are the anatomy and the electrophysiological responses: different species have unique characteristic frequencies, threshold curves and frequency ranges. Our results show that the pattern of the metabolic response of the mouse is not a general feature of auditory systems. While all peripheral tissues, including those of the cochlear lateral wall, are responsive to stimulation in the gerbil, the pattern differs from the mouse in two aspects. First, there is a linear increase with elevated noise levels without indication of a biphasic response for the intensities investigated. Secondly, at moderate sound intensities, the gerbil shows approximately half the metabolic stimulation of the mouse. These findings apparently agree with those of Ryan et al. (1982), who by autoradiographic analysis found little increases of deoxyglucose uptake with noise stimulation in the gerbil.

The guinea-pig was chosen for comparisons because of its well characterized auditory system. Moreover, cochlear perfusions provide a convenient means of direct and continuous deoxyglucose application while allowing manipulation and control of cochlear function. Perilymphatic glucose has been demonstrated to be a substrate for maintaining cochlear potentials (Kambayashi et al., 1982), but we did not observe a stimulus related increase of deoxyglucose uptake into auditory tissues. Since the route of administration bypasses the blood circulation this could indicate that blood flow is mediating the response to acoustic stimulation in analogy to coupling of blood flow and metabolism in brain (Reivich, 1974). However, it should be kept in mind that the perfusion requires the animal remaining anesthetized during the experiment, and this may affect metabolism (Sokoloff et al., 1977).

In conclusion, the magnitude of the metabolic stimulation of auditory tissues and the pattern of the dose-response relationship varies with species and possibly the route of precursor administration. However, our results indicate that the cochlear dysfunctions investigated in these animal models are characterized by abnormal evoked metabolism. Assessments of auditory metabolism in other well characterized disorders should shed more light on the relationship between cochlear metabolism and pathology but such studies must utilize defined sound stimulus levels and generalizations across species should be made with great caution.

Acknowledgements - The authors wish to acknowledge the National Institute on Aging for providing the aged CBA mice. This work was supported by research grant NS-12881 and program project grant NS-05785 from the National Institutes of Health. 


\section{REFERENCES}

Alavi A., Reivich M., Greenberg J., Hand P., Rosenquist A., Rintelmann W., Christman D., Fowler J., Goldman A., MacGregor R. and Wolf A. (1981) Mapping of functional activity in brain with $\left[{ }^{18} \mathrm{~F}\right]$-Fluoro-deoxyglucose. Sem. Nucl. Med. XI, 24-31.

Canlon B. and Schacht J. (1983) Acoustic stimulation alters deoxyglucose uptake in the mouse cochlea and inferior colliculus. Hearing Res. 10, 217-226.

Crowley D. E., Swain R. E. and Schramm V. L. (1972) Analysis of age-related changes in electrical responses from the inner ear of rats. Ann. Otol. 81, 739-749.

Hassell J. A., Colby C. and Romano A. (1975) The effect of serum on the transport and phosphorylation of 2-deoxyglucose by untransformed and transformed mouse 3T3 cells. J. Cell Physiol. 86, 37-45.

Johnsson L.-G. and Hawkins J. E., Jr. (1972) Sensory and neural degeneration with aging, as seen in microdissections of the human inner ear. Ann. Otol. 81, 179-193.

Kambayashi J., Kobayashi T., Marcus N. Y., DeMott J. E., Thalmann I. and Thalmann R. (1982) Minimal concentrations of metabolic substrates capable of supporting cochlear potentials. Hearing Res. 7, 105-114.

Keithley E. M. and Feldman M. L. (1982) Hair cell counts in an age-graded series of rat cochleas. Hearing Res. 8 , 249-262.

Lowry O. H., Rosebrough N. J., Farr A. L. and Randall R. J. (1951) Protein measurement with the Folin phenol reagent. J. biol. Chem. 193, 265-275.

Maass B, (1981) Physiological and pathological aspects of inner ear circulation. Proc XIIth ORL World Congr. (Edited by Surjan L. and Bodo Gy.), pp. 607-609. Hungarian Academy of Science, Budapest.

Massoni A. (1969) Internal auditory canal arterial relations at the porus acusticus. Ann. Otol. 78, 797-814.

Mikaelian D. O. (1979) Development and degeneration of hearing in the $\mathrm{C} 57 / \mathrm{bl} 6$ mouse: relation of electrophysiologic responses from the round window and cochlear nucleus to cochlear anatomy and behavioral responses. Laryngoscope $89,1-15$.
Pestalozza G., Davis H., Eldredge D. H., Covell W. P. and Rogers J. B. (1957) Decrcased bio-clectric potentials in the ears of senile guinea pigs. Laryngoscope 67, 1113-1122.

Phelps M. E., Huang S. C., Hoffman E. F., Selin M. S., Sokoloff L. and Kuhl D. E. (1979) Tomographic measurement of local cerebral glucose metabolic rate in humans with (F-18)2-fluoro-2-deoxyglucose: Validation of method. Ann. Neurol. 6, 371-388.

Reivich M. (1974) Blood flow metabolism couple in brain. Res. Publs Ass. Res. nerv. ment. Dis. 53, 125-140.

Reivich M., Kuhl D., Wolf A., Greenberg J., Phelps N., Ido T., Casella V., Fowler J., Gallager B., Hoffman E., Alavi A. and Sokoloff L. (1977) Measurement of local cerebral glucose metabolism in man with ${ }^{18} \mathrm{~F}$-2-fluor2-deoxy-D-glucose. Acta Neurol. scand. (Suppl.) 56(64), 190-191.

Ryan A. F., Goodwin P., Woolf N. K. and Sharp F. (1982) Auditory stimulation alters the pattern of 2-deoxyglucose uptake in the inner ear. Brain Res. 234, 213-225.

Smith C. B., Goochee C., Rapoport S. I. and Sokoloff L. (1980) Effects of aging on local rates of cerebral glucose utilization in the rat. Brain 103, 351-365.

Sokoloff L. (1981) The deoxyglucose method for the measurement of local glucose utilization and the mapping of local functional activity in the central nervous system. Int. Rev. Neurobiol. 22, 287-333.

Sokoloff L., Reivich R. M., Kennedy C., Des Rosiers M. H., Patlack C. S., Pettigrew K. D., Sakurada O. and Shinohara M. (1977) The ${ }^{14} \mathrm{C}$-deoxyglucose method for measurement of local cerebral glucose utilization. $J$. Neurochem. 28, 897-916.

Takada A. and Schacht J. (1982) Calcium antagonism and reversibility of gentamicin-induced loss of cochlear microphonics in the guinea pig. Hearing Res. 8, 179-186.

Takei H., Fredericks W. R., London E. D. and Rapoport S. I. (1983) Cerebral blood flow and oxidative metabolism in conscious fischer-344 rats of different ages. J. Neurochem. 40, 801-805.

Thalmann R., Miyoshi T. and Thalmann I. (1972) The influence of ischemia upon the energy reserves of inner ear tissues. Laryngoscope 82, 2249-2272. 